\title{
Profiling Inflammatory Genes and Signaling Pathways in Rheumatoid Synoviocytes for RA Light Therapy
}

\author{
Yasuko Shibata and Yoshimitsu Abiko \\ Department of Biochemistry and Molecular Biology \\ Nihon University School of Dentistry at Matsudo \\ Japan
}

\section{Introduction}

Rheumatoid arthritis (RA) is an autoimmune joint disease characterized by inflammation and destruction of the articular surfaces and bone. During joint movement, synovial tissues contribute to mechanical load bearing by changing their shape. These elastic synovial membranes are an early target of rheumatic inflammation, and together with chondrocytes, become a primary source of inflammatory factors (e.g., cytokines) that enter the synovial fluid (Dayer, 2004, Firestein, 2007). The pathophysiological steps leading to RA include inflammation, proliferation of synovial cells, and attachment to and invasion of adjacent cartilage and bone by fibroblast-like cells derived from rheumatoid synoviocytes (RA-FLSs) (Firestein, 1996, Pap et al., 2000, Tolboom et al., 2005, Bartok \& Firestein, 2010).

In the healthy synovium, one to three layers of synoviocytes, the macrophage-like type A and the more abundant fibroblast-like type B (also referred to as synovial fibroblasts), form the synovial lining layer separating the synovial sublining layer of loose connective tissue from the joint cavity (Iwanaga et al., 2000). The joint damage observed in RA is mainly mediated by macrophage/macrophage-like cell-derived cytokines, such as interleukin (IL)1, IL-6 and tumor necrosis factor (TNF)- $\alpha$, which induce neutral protease production by FLSs and articular chondrocytes (Houssiau et al., 1988, Feldmann \& Maini, 1999, Dayer, 2002). Although IL-1 and TNF- $\alpha$ share many biological activities that are relevant in RA, early studies of experimental arthritis models have demonstrated that IL-1 plays a predominant role in cartilage destruction via inflammatory processes that include the activation of matrix metalloproteinases (MMPs) (Borghaei et al., 1998) and the inhibition of the synthesis of extracellular matrix (ECM) molecules (Mauviel et al., 1988). In particular, IL$1 \beta$ is readily detected, long after the onset of RA, at high levels in the synovial fluid of RA patients. IL-1 $\beta$ can significantly alter the expression of a variety of genes, including inflammatory mediators such as cytokines and MMPs (Sun \& Yokota, 2002, Suzuki et al., 2010). In addition, IL-1 stimulates bone resorption by activating osteoclasts (Goldring, 2003). That said, there is little comprehensive information available on the effects of IL-1 $\beta$ on fibroblast-like synoviocytes (FLSs).

RA-FLSs not only mediate tissue destruction, but also are considered to play a major role in initiating and driving RA in concert with inflammatory cells (Huber, 2006, Bartok \& 
Firestein, 2010). However, the original roles of single RA-FLS, and their relationship with macrophage-like type B cells in the rheumatoid synovium are poorly understood, although many case reports of RA patients, and many experimental reports using the synovium tisuues/cells from RA patients have been published. The utilization of cells such as the MH7A human RA-FLSs (Cell Bank, Riken Bioresource Center, Ibaraki, Japan), which are established cells isolated from the knee joint of an RA patient that retain the morphological and functional characteristics of primary synovial cells should provide guidance to clarify the mechanisms of onset of RA and to the development of useful treatments for RA. The MH7A cells are an immortalized RA-FLS line that stains positively for IL-1R, intercellular adhesion molecule-1 (ICAM-1), CD16, CD40, CD80, and CD95 and has been used extensively to investigate the molecular mechanisms underlying RA (Miyazawa et al., 1998). It has been shown, for example, that IL-1 $\beta$ enhances the production of IL-6, IL-8, and MMPs in MH7A cells (Shibata et al., 2005, Han et al., 2006) in a manner similar to that seen in the parental FLSs, although the immortalized cells grow more rapidly than the parental cells. These results clearly indicate the usefulness of MH7A cells for investigating the regulation of rheumatoid FLSs and the IL-1 signal transduction pathway to develop a future RA therapy.

In what is becoming known as the "post-genomic era", many new technologies and methodologies are being developed to take advantage of the recent progress in genomic research. Among these, gene expression profiling has become an invaluable tool in functional genomics. DNA microarrays, cDNA subtraction, and the serial analysis of gene expression have all emerged as leading transcript profiling technologies for the global analysis of biological systems. One of the high throughput technologies, high-density oligonucleotide genechip microarrays, makes it possible to simultaneously measure the relative abundance of numerous mRNAs within a cell. To better understand the direct IL$1 \beta$-induced changes in gene expression that might promote inflammatory responses in MH7A cells, in the present study we used an Affymetrix HG-8500 Focus array GeneChip to analyze the patterns of gene expression, and then used the Ingenuity Pathway Analysis (IPA) software program to investigate the signaling pathways leading to the IL-1 $\beta$-induced gene expression. In addition, we used a biotin label-based antibody array to measure the levels of 507 human target proteins, including cytokines, chemokines, growth factors, angiogenic factors, proteases, and soluble receptors, among others, in the cell culture supernatants. We analyzed the expression profiles of both the genes and proteins to identify the key molecules involved in articular rheumatism, which could be related to the induction of inflammation and pannus formation in the synovial tissues of RA patients. In addition, we propose the possibility of a new therapy using linear polarized infrared light, that induces the suppression of inflammation and pain for RA patients with no apparent sideeffects.

\section{Microarray analysis}

MH7A human RA-FLSs (Riken Bioresource Center, Ibaraki) were maintained in RPMI 1640 medium supplemented with $10 \%$ fetal calf serum (FCS) and penicillin-streptomycin at $37^{\circ} \mathrm{C}$ under a $5 \% \mathrm{CO}_{2}$ atmosphere. Total RNA from the MH7A cells was treated according to the manufacturer's protocol, and then hybridized to a Human Genome Focus Array HG-8500 GeneChip (Affymetrix Inc.). 
Our aims were to identify potential mediators of RA inflammation and joint destruction induced by the inflammatory cytokine IL-1 $\beta$, and to investigate the mechanisms responsible for their stimulation. Of the 8,746 genes on the Focus array HG-8500 GeneChip, 4,909 from untreated cells and 5,073 from IL-1 $\beta$-treated cells were classified as marginally expressed or present. After the cut-offs for induction ( $\geq 2.0$-fold) and suppression ( $\leq 0.5$-fold) by IL- $1 \beta$ were applied, 120 genes (74 upregulated and 46 downregulated genes) were identified as being affected by IL-1 $\beta$. When we then classified the IL-1 $\beta$-inducible gene expression in MH7A cells with respect to six functionalities based on BiologicalProcess words, we found that IL-1 $\beta$ conspicuously increased the expression of inflammation and apoptosis/proliferation-related genes, although the largest group of genes affected by IL-1 $\beta$ was signaling-related (Fig. 1).

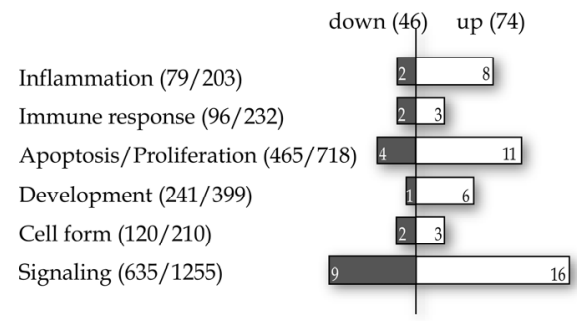

The genes that were upregulated $(n=74)$ or down-regulated $(n=46)$ by IL-1 $\beta$ were classified into 6 groups based on the GO-BiologicalProcess terms listed in the GeneSpring 6.2 software program.

Fig. 1. Classification of genes whose expression in MH7A cells was affected by IL-1 $\beta$.

We used IPA to gain a better understanding of how differentially expressed genes were integrated into specific regulatory and signaling networks. A data set containing gene identifiers adhering to the 2-fold (120 genes) change used in microarray experiments was uploaded into the IPA software application. Each gene identifier was mapped to its corresponding gene object and then overlaid onto a global molecular network developed from information contained in the Ingenuity Pathways Knowledge Base. The networks of these genes were then algorithmically generated based on their connectivity, after which a functional analysis of the networks identified the biological functions that were the most significant.

\subsection{IL-1 $\beta$-induced inflammatory signaling pathways}

We attempted to visualize the IL-1 $\beta$-induced genes within the canonical IPA pathway, which involves IL-1 $\beta$, IL-6, and TNF- $\alpha$ signaling (Fig. 2A, canonical pathway name: IL-6 signaling). Four IL-1 $\beta$-inducible genes (>2.0-fold), IL-1 $\beta$, IL-6, IL-8, and I $\mathrm{B}$, were situated within this atlas. As shown in Fig. $2 \mathrm{~A}$, activation of NF- $\kappa \mathrm{B}$ signaling is also important for the secretion of IL-8, IL-1 $\beta$ and IL-6. We previously used an ELISA to show that TNF- $\alpha$ was not expressed in MH7A cells, regardless of whether they were exposed to IL-1 $\beta$ (0.1 unit/ml) (Shibata et al., 2005). Likewise, the results we obtained using the GeneChip microarray indicated no expression of TNF- $\alpha$ in MH7A cells under our experimental conditions. IL-1 $\beta$ did induce its own expression, which may be important for its accumulation during the inflammation in RA. Furthermore, high levels of NF-IL6 (CEBPB) expression were consistently observed. 


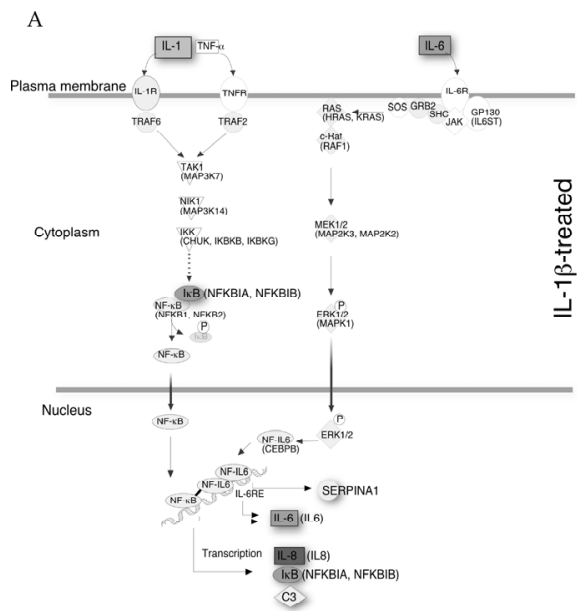

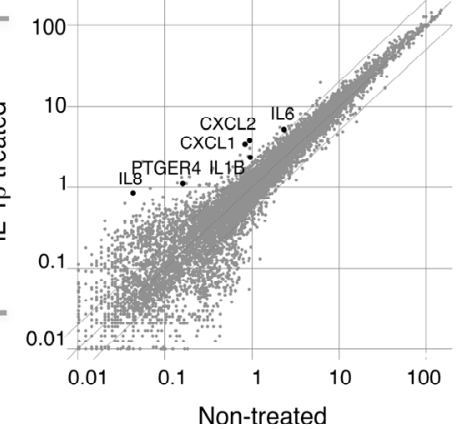

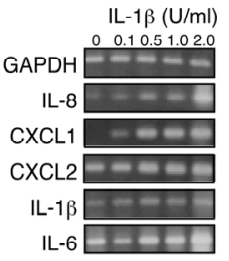

A. The IL-1 $\beta$ and IL-6 signaling pathways as determined by IPA analysis. Grayed symbols indicate genes that were upregulated by IL-1 $\beta$; white symbols indicate genes whose expression was not increased by IL-1 $\beta$. B. A scatter plot of 8,793 genes. Genes whose expression ratio was changed by $>2-$ fold by IL-1 $\beta$ are positioned outside the lines. C. Dose-dependent effects of IL- $1 \beta$ on the gene expression. MH7A cells were examined after treatment with fresh medium containing the indicated concentration of IL-1 $\beta$, and the cells were incubated for an additional $2 \mathrm{hr}$.

Fig. 2. The IL-1 $\beta$ and IL-6 signaling pathways and the results of the RT-PCR analysis

Based on the structural analysis, the chemokine superfamily can be divided into two groups: the C-X-C and the C-C subfamilies (Baggiolini et al., 1994). IL-8 belongs to the first group and acts mainly on neutrophils (Hebert \& Baker, 1993). Our microarray experiments showed that IL-8 transcription was the most dramatically upregulated (20.8 fold) in MH7A cells exposed to IL-1 $\beta$. It is also noteworthy that the expression of other chemokines, including CXCL-1 (4.1-fold), -2 (4.0-fold) and -3 (2.7-fold), three potent stimulators of neutrophil activation and tissue infiltration was also enhanced. Leukocyte recruitment from the microvasculature to sites of inflammation is a sequential process that includes rolling, activation, firm adhesion, and finally, transmigration through the vessel wall (King \& Hammer, 2001). Although macrophages, neutrophils, and endothelial cells are all thought to be primary sources of IL-8, which is known to be elevated at inflammatory sites such as the synovial fluid of RA patients, fibroblast-like and macrophage-like cells of the synovial membrane, together with the infiltrating leucocytes, are the major source of these mediators in the rheumatoid synovial pannus (Rathanaswami et al., 1993). In the GeneChip microarray experiment, an IL-1 $\beta$ concentration close to the levels seen clinically was used to stimulate the MH7A cells. The gene expression of IL-8, Gro- $\alpha$ (CXCL1), Gro- $\beta$ (CXCL2), IL-1 $\beta$, and IL6 in scatter plots is shown in Fig. 2B. According to a RT-PCR analysis, the levels of IL-8, CXCL1, CXCL2, IL-1 $\beta$, and IL-6 mRNA in MH7A cells were all found to be dosedependently increased by IL-1 $\beta$ (Fig. 2C). Therefore, IL-8 appears to play a major role in the initiation and maintenance of inflammatory responses.

Within the $5^{\prime}$-flanking region of the human IL-8 promoter are a number of motifs with the potential to bind various transcription factors in a cell and stimulus-dependent manner. In particular, the transcription factors NF- $\mathrm{BB}$ and NF-IL-6 are both involved in stimulus- 
induced IL-8 expression (Matsusaka et al., 1993). We would therefore anticipate that these transcription factors would play an important role in the increased expression of IL-8

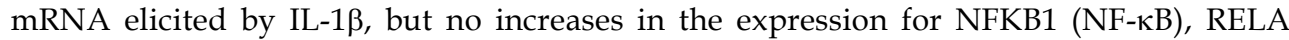
(RelA), or CEBPB (NF-IL-6) were seen in the microarray experiment. On the other hand, in resting cells, NF- $\mathrm{BB}$ is trapped in the cytoplasm through its interaction with its inhibitor, $\mathrm{IkB}$, and a crucial step in the activation of NF- $\mathrm{KB}$ is the stimulus-induced phosphorylation

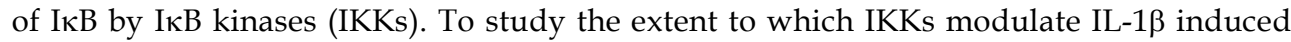
IL-8 production, MH7A cells were pretreated with Bay11-7085, an inhibitor of IкB phosphorylation, for $1 \mathrm{hr}$ before stimulation with IL-1 $\beta$ (Shibata et al., 2009a). As shown in Fig. 3, Bay11-7085 completely blocked the release of IL-8 from IL-1 $\beta$-stimulated MH7A cells.

A

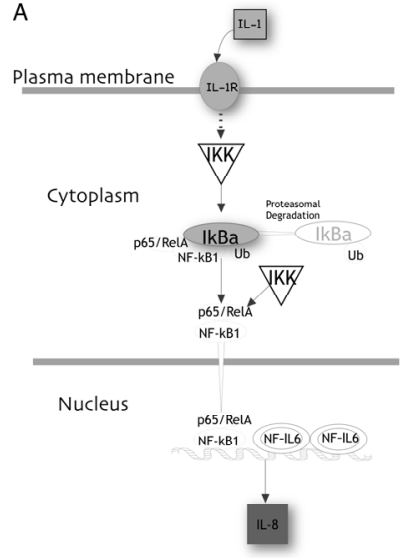

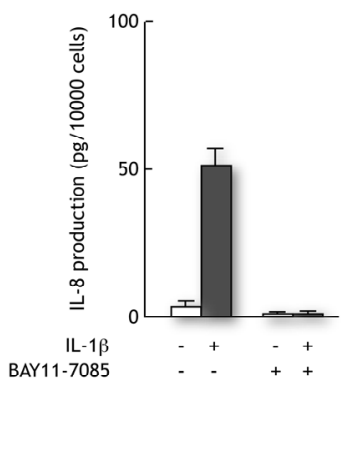

A. The IL-1 $\beta$-induced signal transduction pathways leading to the production of IL-8. Gray symbols indicate genes that were up-regulated by IL- $1 \beta$. White symbols indicate genes whose expression was increased less than 2.0-fold by IL-1 $\beta$. B. The effects of Bay11-7085 on the production of IL-8. MH7A cells were first incubated with the IKK $\alpha / \beta$ inhibitor Bay11-7085 for $1 \mathrm{hr}$, and then with IL-1 $\beta$ for $2 \mathrm{hr}$. The levels of IL-8 in medium conditioned by the cells were measured using an ELISA. [This figure is modified from (Shibata et al., 2009a)]

Fig. 3. The effect of Bay11-7085 on the production of IL-8

\subsection{Arithmetic IL-8 production through the $\mathrm{PGE}_{2}$ receptor synthesis}

$\mathrm{PGE}_{2}$, a product of the cyclooxygenation of arachidonic acid, is a potent mediator of the immune response and inflammation, and contributes to the pathogenesis of RA (Robinson et al., 1975, Trebino et al., 2003). PGE 2 also displays a complex regulatory function affecting IL-8 gene expression, which is dependent on the concentration of $\mathrm{PGE}_{2}$ and on the specific cell type involved. At physiological and pathological concentrations of up to $100 \mu \mathrm{M}, \mathrm{PGE}_{2}$ is capable of upregulating endogenous IL-8 expression in human colonic epithelial cells (Yu \& Chadee, 1998). However, there have been many reports that $\mathrm{PGE}_{2}$ has no effect on neutrophil-derived IL-8 induced by LPS (Wertheim et al., 1993); that it down-regulates IL-8 in response to LPS in human alveolar macrophages and blood monocytes (Standiford et al., 1992); and suppresses the production of chemokines, including IL-8, in human macrophages 
(Takayama et al., 2002). Furthermore, $\mathrm{PGE}_{2}$ alone had little detectable effect on IL-8, although a small enhancement of the mRNA and protein levels of IL-6 has been observed in human synovial fibroblasts (Agro et al., 1996). In RA research, while $\mathrm{PGE}_{2}$ alone has limited effects on synovial cell production of IL-8, its effects are significant in the context of IL-1 $\alpha$ stimulation; endogenous $\mathrm{PGE}_{2}$ may alter the cytokines secreted by mesenchymally-derived cells.

A variety of transcription factors, including NF- $\mathrm{B}$, NF-IL6, activator protein-1 and octamer1, have been shown to regulate IL-8 gene transcription (Matsusaka et al., 1993). Caristi et al (Caristi et al., 2005) have shown that, in human T cells, PGE 2 induces IL-8 synthesis through an NF-kB-independent pathway via its EP1- and EP4-type receptors (PGE2EP1 and PGE2EP4, respectively). We have demonstrated that $\mathrm{PGE}_{2}$ at physiological, as well as pathological, concentrations induced IL-8 production thorough the increased expression of PGE2EP4 receptors in synovial fibroblasts of RA in vitro (Shibata et al., 2009b). The present results were of particular interest, since the effect of $\mathrm{PGE}_{2}$ on IL-8 production was found in the IL-1 $\beta$-pretreated MH7A cells. We demonstrated that the newly expressed-PGE 2 receptors are involved in this process.

These findings show the complexity with which $\mathrm{PGE}_{2}$ regulates IL-8 synthesis by inhibiting or enhancing its production depending on the cell types and environmental conditions. Therefore, we proposed that, in IL-1 $\beta$-stimulated synovial fibroblasts in RA patients, $\mathrm{PGE}_{2}$ induces IL- 8 mRNA transcription by the activation of different signal transduction pathways from the conventional IL-1 $\beta$-stimulated pathways, including $\mathrm{PGE}_{2}$ receptor EP4-triggered pathways. IL-1 $\beta$ enhanced the gene expression of IL8 and PTGER4 (Shibata et al., 2009b), subsequently IL-8 production was enhanced by IL-1 $\beta$ and PGE 2 from environmental neutrophils/macrophages in the synovial tissues. These results may therefore highlight a new important role for $\mathrm{PGE}_{2}$ in regulating IL-8 production by the synovial fibroblasts of RA patients, confirming the pro-inflammatory activity of this prostaglandin.

\subsection{Apoptotic signaling}

Inflammation of the synovial membrane results in the development of aggressive granulation tissue, called "pannus". Pannus tissue is composed mainly of inflammatory cells such as macrophages and FLSs. By a microarray analysis, the apoptosis/proliferation-related molecules included those involved in processes associated with negative/positive regulation of cell proliferation, apoptosis/anti-apoptosis, cell death, cell proliferation and regulation of the cell cycle, and a large number of these genes were influenced by IL-1 $\beta$ (Fig. 1). Interestingly, whereas the expression of the gene encoding the apoptosis inhibitor CIAP (BIRC3) was enhanced (4.8-fold), the expression of those encoding the cell death inducing molecule FOSL2 (FOS-like antigen 2, 0.4-fold)) and the cell proliferation-related molecule EDNRA (endothelin receptor type A, 0.2-fold) were both suppressed. We attempted to apply the IL-1 $\beta$-inducible genes to a typical pathway atlas involving apoptotic signaling (Fig. 4A). The expression of BIRC3, which encodes the anti-apoptotic protein CIAP, implies that IL-1 $\beta$ signaling leads to inhibition of apoptotic signaling, as expression of cIAP should exert an inhibitory effect on caspase 3 activity (Rothe et al., 1995, Budihardjo et al., 1999). To confirm the increased cIAP production in MH7A cells, we found that levels of the BIRC3 transcript were substantially increased in the IL-1 $\beta$-induced MH7A cells (Fig. 4B). 
A

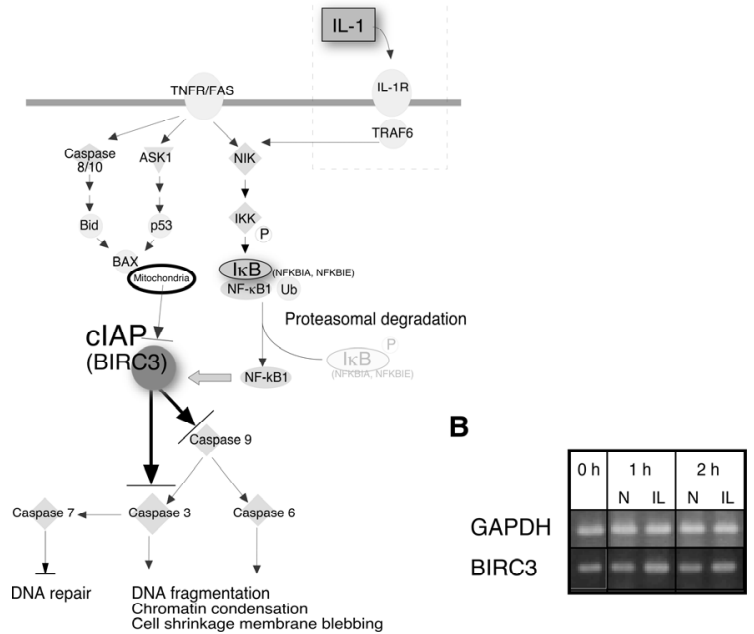

A. The gray symbols indicate the IL-1 $\beta$-inducible genes (>2.0-fold) in the apoptosis signaling pathway. B. The time-dependent effects of IL-1 $\beta$ on the gene expression of cIAP (BIRC3), which negatively regulates apoptotic signaling, were examined using MH7A cells.

Fig. 4. An atlas of an apoptosis signaling pathway

It has been suggested that RA is driven by a network of closely connected interdependent pathogenic mechanisms involving innate and adaptive immunity that ultimately lead to synovial inflammation and aggressive synovial overproliferation during the terminal destructive phase (Firestein, 2003). Furthermore, in a chronically inflamed microenvironment, these destructive changes are driven by invasive synovial hyperplasia and neovascularization (pannus formation) at the interface between the synovium and intraarticular space. During the process of synovial pannus formation, FLSs actively contribute to the inflamed and destructive local microenvironment by secreting a variety of inflammatory mediators, which lead to tissue degradation. In response to IL-1 and TNF- $\alpha$, FLSs also secrete angiogenic growth factors, such as vascular endothelial growth factor (VEGF) (Nagashima et al., 1999) and basic fibroblast growth factor (bFGF), which are essential for the pathophysiological neovascularization in RA joints. In addition, we have identified that BIRC3 is upregulated, making it a candidate mediator of FLS overproliferation in RA. BIRC3 encodes cIAP, which is a key negative regulator of apoptotic signaling in FLSs. The resulting inhibition of FLS apoptosis in the inflamed area would be expected to contribute to the formation of the pannus in the RA joint.

\section{Protein chip analysis}

\subsection{ECM degradation}

A RayBio biotin label-based human antibody array I (RayBiotech, Inc.) was used to measure the expression levels of 507 proteins in culture medium conditioned by MH7A cells. Table 1 presents the results of the biotin label-based antibody array analysis of secreted proteins that categorized interleukins, and molecules involved in ECM metabolism. IL-12 p70 and IL-8 were 
both abundantly expressed in the IL-1 $\beta$-induced MH7A cells (57.8- and 12.6-fold increases, respectively). IL-12 is a heterodimer expressed in RA synovial tissue (Morita et al., 1998); dendritic cells and macrophages produce IL-12 within minutes of activation, and it plays a central role in the development of Th1 responses (Hunter, 2005). The biological functions of these cells are not yet fully understood, but they are known to play a role in the differentiation and proliferation of T cells of the Th1 phenotype. Th1 responses in turn are deemed to be of particular importance in inflammatory arthritis, including RA. This induction of IL-12p70 by IL-1 $\beta$ in MH7A cells may be the first in vitro evidence of IL-12 expression in RA. This is noteworthy, because Connell \& McInnes (Connell \& McInnes, 2006) suggested in their review that IL-12 likely contributes to the pathology of inflammatory joint disease. If this is the case, it may represent a potentially useful therapeutic target.

\begin{tabular}{|c|c|c|c|c|c|}
\hline \multirow{2}{*}{ Fold } & \multirow{2}{*}{ Protein Name } & \multicolumn{2}{|c|}{ Non-treated } & \multicolumn{2}{|c|}{ IL-1b-treated } \\
\hline & & Normalized & Raw (n=3) & Normalized & $\operatorname{Raw}(n=3)$ \\
\hline \multicolumn{6}{|l|}{$\overline{\text { ILs }}$} \\
\hline 57.8 & IL-12 p70 & 0.01 & nd & 0.58 & $3384 \pm 104$ \\
\hline 12.6 & IL-8 & 0.01 & nd & 0.13 & $737 \pm 104$ \\
\hline 2.6 & IL-16 & 0.01 & $49 \pm 99$ & 0.03 & $162 \pm 54$ \\
\hline \multicolumn{6}{|l|}{ MMPs } \\
\hline 3.7 & MMP-10 & 0.01 & nd & 0.04 & $219 \pm 44$ \\
\hline 2.3 & MMP-11 (Stromelysin-3) & 0.01 & nd & 0.02 & $134 \pm 26$ \\
\hline \multicolumn{6}{|l|}{ TIMPs } \\
\hline 0.3 & TIMP-1 & 0.72 & $3270 \pm 1051$ & 0.24 & $1395 \pm 129$ \\
\hline 0.4 & TIMP-3 & 0.28 & $1296 \pm 65$ & 0.11 & $643 \pm 296$ \\
\hline
\end{tabular}

RayBio biotin label-based human antibody array I (RayBiotech, Inc.) was used to measure the expression levels of 507 proteins in culture medium conditioned by MH7A cells. The cell were cultured for $16 \mathrm{~h}$ and then treated with IL-1 $\beta(0.1 \mathrm{U} / \mathrm{ml})$ for $3 \mathrm{~h}$. The cultured medium from five wells was then combined and dialyzed against PBS ( $\mathrm{pH} 8.0$ ), and an internal control protein was added to the $400 \mu \mathrm{l}$ of dialyzed sample medium. The procedure used for biotin labeling, blocking and incubation of the antibody array, as well as fluorescence detection were carried out according to the operating manual from RayBiotech. The images were captured using an Axon GenePix laser scanner. Biotinylation of the internal control protein yielded a positive control signals that was used to identify the orientation of the results and help normalize them for comparison of those from the untreated and IL-1 $\beta$-treated MH7A cell arrays. Values below 0.01 were set to 0.001 .

Table 1. IL-1 $\beta$-induced protein.

On the other hand, the levels of two MMP family enzymes, MMP-10, and MMP-11 were upregulated by IL-1 $\beta$, while the levels of TIMP- 1 and -3 were downregulated. As the overall MMP activity reflects a balance between the amount of MMPs and TIMPs present, the reduction in TIMP-1 and TIMP-3 levels seen in MH7A cells would be expected to shift the balance in favor of increased MMP activity. Taken together, these data suggest that IL-1 $\beta$ elicits a series of responses in the synovial fluid, leading to the pathology seen in RA, including enhanced expression of inflammatory cytokines and enzymes, and a reduction in the ability to protect against the destruction of the tissue ECM. 


\section{Medical treatments for RA}

Several disease-modifying anti-rheumatic drugs (DMARDs) have been used to control the progression of RA. While the majority of these drugs act as immunomodulatory agents, some also act by inhibiting cytokines and endothelial cell proliferation (Cozzolino et al., 1993, Volin et al., 1999). Newly developed biological response modifiers (biologics) offer even more hope, having a greater potential to suppress disease activity, and improve the quality of life of RA patients.

\subsection{Disease-modifying anti-rheumatic drugs, TNF- $\alpha$ blockers, and other agents}

Guidelines advocate treatment with DMARDs as soon as RA is diagnosed to control symptoms and delay disease progression (Smolen \& Steiner, 2003, O'Dell, 2004, Saag et al., 2008). DMARDs slow the progression of the joint damage that leads to loss of function, whereas drugs such as nonsteroidal antiinflammatory drugs and corticosteroids only control the symptoms (Kirwan \& Power, 2007). On the other hand, targeted inhibition of TNF- $\alpha$ is an effective therapy widely used against RA and other rheumatic diseases. The advent of TNF blockers has led to substantial improvement in the management of active RA refractory to conventional DMARDs. While on a patient-population level, the efficacy of the TNF blockers infliximab, etanercept, and adalimumab seems comparable, on an individual level, there are no clear-cut methods for assessing whether there will be a response to antiTNF therapy, let alone which agent would yield the best outcome. The updated consensus statement on biological agents for the treatment of rheumatic diseases states that the optimal treatment for anti-TNF refractory RA remains to be determined. However, most importantly, it is not yet possible to identify prior to therapy which patients will fail to respond or who are at increased risk for adverse drug reactions (Mendonça et al., 2011). Given the important role that TNF- $\alpha$ antagonists play in managing rheumatoid arthritis and the concern for safety during long-term therapy, such factors need to be determined as soon as possible.

Glucocorticoids have potent immunosuppressive effects and have been widely used in the management of chronic inflammatory diseases such as severe RA. A number of studies have focused on the cellular and molecular mechanisms underlying the anti-inflammatory effects of glucocorticoids such as dexamethasone (Dex). Glucocorticoids exert their effects via intracellular receptors that act as potent transcriptional activators of genes that possess glucocorticoid responsive elements. By regulating gene expression, glucocorticoids suppress the production of pro-inflammatory proteins, such as cytokines, chemokines and some enzymatic mediators. However, the therapeutic management of long-term pathological conditions with steroids is often linked to unwanted side effects involving the cardiovascular system (Suissa et al., 2006).

\subsection{Proposal of RA therapy using linear polarized infrared light}

It is unclear whether early treatment with biologics should continue to be recommended, given their potential to slow disease progression and extend productivity on the one hand, while causing unwanted side effects and risks due to drug-associated health care utilization on the other. Therefore, we examined the potential of photodynamic therapy using a linear polarized infrared light (LPIL). Laser therapy is a new arthroscopic technique to treat inflammation of the synovial membrane. Following gallium-aluminum-arsenide (Ga-Al-As) 
laser treatment, histological examination of the irradiated synovial membranes showed flattening of the epithelial cells, decreased villous proliferation, narrower vascular lumens and less infiltration by inflammatory cells than was seen in non-irradiated synovia. An alternative approach makes use of a linear polarized infrared light (LPIL) instrument (Super Lizer $^{\mathrm{TM}}$, Tokyo Iken Co., Ltd), which has been used clinically with good effects in several patients with inflammatory disease. LPIL can be applied during physical therapy to relieve pain, and several studies have shown that such irradiation also relieves temporomandibular joint pain (Yokoyama \& Oku, 1999), improves the structure of stored human erythrocytes (Yokoyama \& Sugiyama, 2003), and improves the flexibility of shoulder and ankle joints (Demura et al., 2002). A fuller understanding of the anti-inflammatory mechanism of LPIL in rheumatoid synoviocytes could serve as the basis for improved treatment of RA patients in the future.

We treated MH7A cells IL-1 $\beta(0.1 \mathrm{U} / \mathrm{ml})$ and/or Dex $(1 \mu \mathrm{M})$ or LPIL $\left(3.8 \mathrm{~J} / \mathrm{cm}^{2}\right)$. Microarray experiments were then carried out using the Affymetrix Focus Array HG-8500 GeneChip. As shown in Fig. 5A, the transcription of numerous genes was up- or down-regulated to a greater degree in cells treated with Dex than in those treated with LPIL. Likewise, the effects of LPIL irradiation on the transcription levels of many genes were smaller than those of IL-

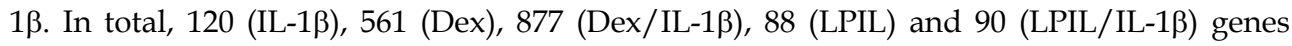
were up- or downregulated by the different treatments (Fig. 5B).

A

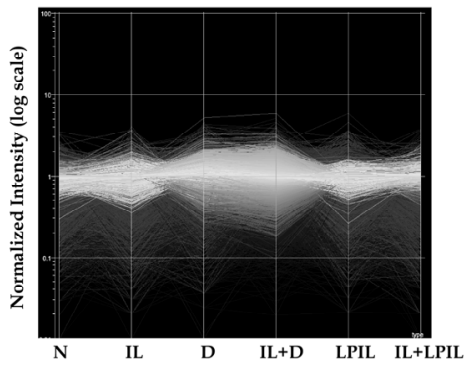

B

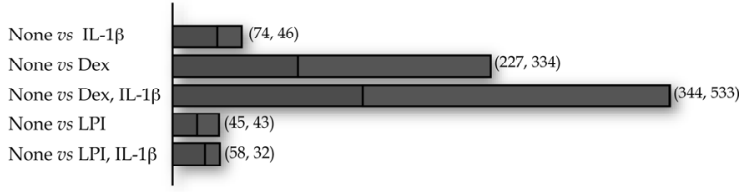

The global gene expression in MH7A cells. The normalized gene expression is shown. MH7A cells were treated with Dex or LPIL in the presence or absence of IL-1 $\beta$ before the extraction of their RNA. N, untreated cells; IL, IL-1 $\beta$-treated cells; D, Dex-treated cells. B. The numbers of up- and down-regulated genes. Genes whose expression was increased or decreased by over two-fold are indicated. [This figure is modified from (Shibata et al., 2009b)]

Fig. 5. Microarray data analysis.

We focused on the genes that were up-regulated by at least 2.0 -fold in cells treated with IL-1 $\beta$ and then suppressed by the anti-inflammatory treatments. IL- 8 transcripts showed the largest increase (20.8 fold), and LPIL and Dex each suppressed this gene expression. Others genes, including CXCL1, 2, 3, IL6, and IL1B, which respectively encode Gro- $\alpha$, Gro- $\beta$, Gro- $\gamma$, IL- 6 and IL-1 $\beta$, were also suppressed by LPIL to the same extent as by Dex (Table 2). Thus, although for the most part LPIL irradiation did not alter the transcription levels to the same degree as Dex did, IL-1 $\beta$ inducible genes, such as the CXCL type chemokines, IL6 and IL1B, were clearly suppressed by LPIL irradiation. To evaluate the 


\begin{tabular}{|c|c|c|c|c|c|c|}
\hline \multirow{2}{*}{ Gene } & \multirow{2}{*}{ Title Affy } & \multicolumn{3}{|c|}{ IL-1 $\beta /$ None } & \multirow{2}{*}{$\begin{array}{c}\text { IL-1 } \beta+\text { Dex } \\
/ \text { None }\end{array}$} & \multirow{2}{*}{$\begin{array}{c}\text { IL-1 } \beta+\text { LPII } \\
\text { /None }\end{array}$} \\
\hline & & Fold & $\begin{array}{l}\text { Normalized } \\
\text { intensity }\end{array}$ & $\begin{array}{l}\text { Raw } \\
\text { Data }\end{array}$ & & \\
\hline IL8 & interleukin 8, CXCL8 & 20.2 & $0.86 / 0.04$ & $(\mathrm{P} / \mathrm{A})$ & 5.6 & 7.6 \\
\hline CXCL1 & $\begin{array}{l}\text { chemokine (C-X-C motif) ligand 1, } \\
\text { GRO1 }\end{array}$ & 4.1 & $3.36 / 0.82$ & $(\mathrm{P} / \mathrm{P})$ & 3.2 & 1.8 \\
\hline CXCL2 & $\begin{array}{l}\text { chemokine (C-X-C motif) ligand 2, } \\
\text { GRO2 }\end{array}$ & 4.0 & $3.78 / 0.94$ & $(\mathrm{P} / \mathrm{P})$ & 2.4 & 3.1 \\
\hline CXCL3 & $\begin{array}{l}\text { chemokine (C-X-C motif) ligand } 3 \text {, } \\
\text { GRO3 }\end{array}$ & 2.7 & $0.85 / 0.32$ & $(\mathrm{M} / \mathrm{A})$ & 3.2 & 2.1 \\
\hline IL6 & Interleukin 6 & 2.7 & $5.51 / 2.07$ & $(\mathrm{P} / \mathrm{P})$ & 1.0 & 2.2 \\
\hline IL1B & Interleukin 1 , beta & 2.5 & $2.33 / 0.92$ & $(\mathrm{P} / \mathrm{M})$ & 1.4 & 1.5 \\
\hline
\end{tabular}

Table 2. Inhibitory effects of anti-inflammatory treatments on IL-1 $\beta$-induced gene expression

inhibitory effects of LPIL irradiation on IL-1 $\beta$ inducible inflammation, we next used an ELISA to monitor IL-1 $\beta$ induced IL-8 synthesis and secretion from MH7A cells. We found that IL-1 $\beta$ strongly induced IL-8 production, and that the effect was similarly suppressed by Dex or LPIL (Fig. 6). We compared the effects of one-time LPIL irradiation and Dex administration on the production of IL-8. Even one period of exposure to LPIL irradiation diminished the IL-1 $\beta$-induced production of IL- 8 to the same extent as administration of 1 $\mu \mathrm{M}$ Dex to the cells. Furthermore, using end-point PCR and real-time PCR, we determined that there were corresponding decreases in the expression of IL-8 mRNA (Fig. 6). It is also noteworthy that the inhibitory effects on IL-8 transcription increased with increasing optical pulse energy.

The genes whose products are involved in NF-KB signaling (e.g., NFKB1, RelA, and C/EBP- $\beta$ ) were not induced by IL-1 $\beta$ stimulation as determined by the microarray analysis. On the other hand, increasing evidence has highlighted the importance of NF- $\mathrm{B}$ modification in the regulation of its transcriptional activity. For instance, it appears that NF- $\kappa \mathrm{B}$ activity can be modulated by phosphorylation of the RelA subunit. Recent evidence indicates that the phosphorylation of the RelA subunit on S276 and S536 is physiologically induced by various proinflammatory stimuli. Zhong et al. (2002) found that LPS stimulates protein kinase A-dependent phosphorylation of RelA on S276 and subsequently recruits the transcription coactivator CREB binding protein (CBP)/p300 to stimulate NF-кB-mediated transcription. Furthermore, it appears that S536 of endogenous cytoplasmic RelA is phosphorylated in response to a wide variety of NF- $\kappa \mathrm{B}$ stimuli and is then rapidly dephosphorylated in the nucleus (Sakurai et al., 1999, Sakurai, 2003, Yang et al., 2003, Mattioli et al., 2004).

Because transduction of the IL-1 $\beta$ signal is tightly regulated in MH7A cells via a network

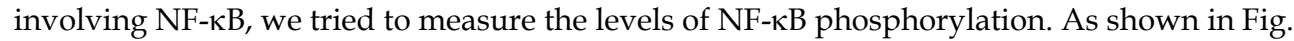
7, the total levels of NF- $\mathrm{KB}$-bound RelA were nearly the same in all of the treated MH7A cells (right panel). Phosphorylation of the RelA subunit on both S276 and S536 was significantly increased by IL-1 $\beta$ stimulation, and was decreased in the presence of Bay11- 
7085 (left and center panels). Interestingly, LPIL irradiation suppressed the phosphorylation of both S276 to the same degree as Dex in IL-1 $\beta$-stimulated MH7A cells.

The extent to which the risk of side-effects may be driven by drugs that decrease immune surveillance (notably, DMARDs including TNF- $\alpha$ blockers, and glucocorticoid agents), is not completely clear. This issue has gained interest in light of reports of serious infections in patients receiving newer RA therapies.
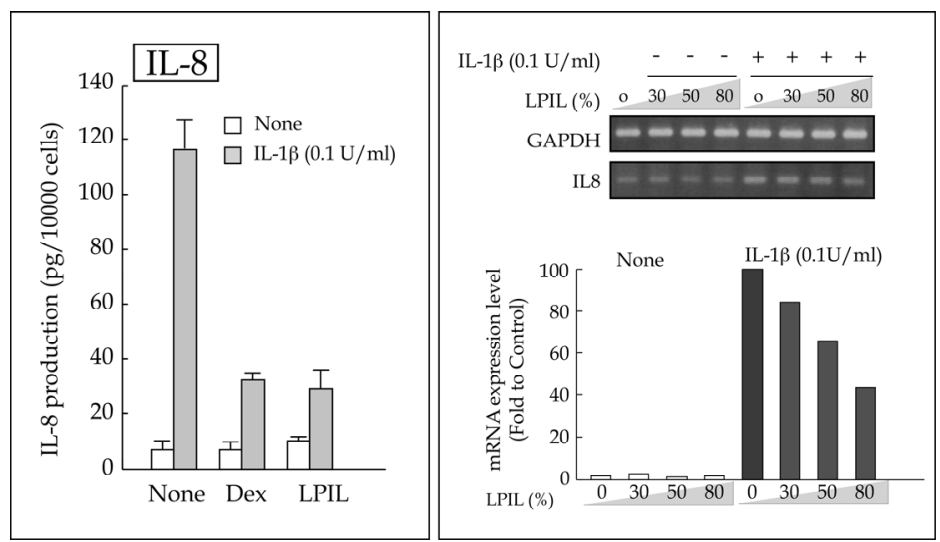

The inhibitory effects of LPIL or Dex on the production of IL-8 in MH7A cells. An end-point PCR analysis shows that LPIL irradiation inhibits IL8, but not GAPDH, gene expression. The power level of the irradiation was changed by adjusting the power dial on the Super Lizer ${ }^{\mathrm{TM}}$ to $30 \%, 50 \%$, or $80 \%$. The duration of the irradiation was the same for all wells. A real-time PCR analysis shows the dose-dependent inhibitory effects of LPIL on IL-8 gene expression. [This figure is modified from (Shibata et al., 2009a)]

Fig. 6. The transcriptional regulation of IL-8 by LPIL and Dex in IL-1 $\beta$-stimulated MH7A cells.

\section{Conclusion}

To study the pathophysiological mechanisms involved in chronic inflammatory disorders such as RA, in vitro culture systems using IL-1 $\beta$-activated FLSs from RA patients have become useful models of the first step in RA-induced joint deterioration. Our findings demonstrate the utility of profiling the gene expression in IL-1 $\beta$ stimulated-MH7A cells, with the supposition that it is representative of the early disease stage of RA. By employing GeneChips and IPA, we were able to show that autocrine induction of IL-1 $\beta$ gene expression may underlie the strong expression of several inflammatory cytokines, including IL- 8 , IL- $1 \beta$ and IL-6, and suggest that continuous IL- $1 \beta$ production has an exacerbating effect on RA. In addition, we have identified upregulation of the BIRC3 gene as a candidate mediator of the FLS overproliferation in RA. BIRC3 encodes CIAP, which is a key negative regulator of apoptotic signaling in FLSs. The resulting inhibition of FLS apoptosis in the inflamed area would be expected to contribute to the formation of the pannus in the RA joint. It is our expectation that further studies of the comprehensive information provided by the GeneChip/IPA analysis and antibody array systems will provide a means to ease the suffering caused by RA. 


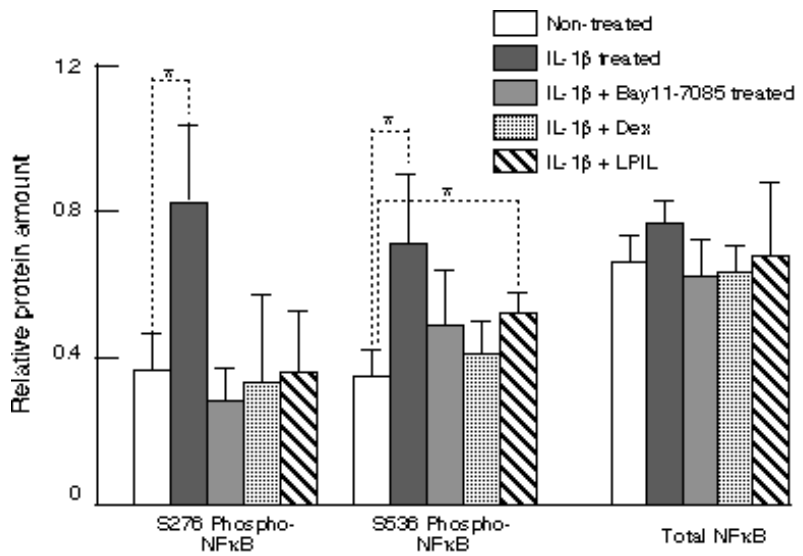

MH7A cells were cultured for $16 \mathrm{~h}$ in 96 well plates and then used to assess the phosphorylation of the NFkB RelA subunit. Cells were irradiated with LPIL for $680 \mathrm{~s}$ immediately after stimulation with IL- $1 \mathrm{~b}$ for $2 \mathrm{~h}$, or Dex was added to cells at the same time as IL-1b. Some cells were pretreated with Bay11-7085 for $1 \mathrm{~h}$ before addition of the IL-1b. After stimulation with IL- $1 \mathrm{~b}$, the culture medium was removed, the cells were fixed by microwaving, and the levels of phosphorylation of the NF-kB RelA subunit on S276 and S536 were measured using a Cellular Activating of Signaling ELISA CASETM kit. The results are expressed as the means $\pm S D(n=6) ;{ }^{*} P<0.005$ vs. untreated. [This figure is modified from (Shibata et al., 2009a)]

Fig. 7. The effects of Bay11-7085, LPIL or Dex on the phosphorylation of S536 and S276 of the NF-kB RelA subunit

IL-8, originally called monocyte-derived neutrophil chemotactic factor, is a potent chemokine, causing recruitment and infiltration of neutrophils and $\mathrm{T}$ cells into local inflammatory sites. The infiltration of neutrophils contributes to inflammation and has been implicated in various diseases. The transcription factors NF- $\kappa \mathrm{B}, \mathrm{AP}-1$, and NF-IL-6 are all involved in the stimulus-induced expression of IL-8. Subsequent IPA revealed that NF- $\mathrm{BB}$ signaling was likely important for the synthesis and release of the IL-8 protein. We then found that IL-1 $\beta$-induced IL-8 release from MH7A cells requires the activation of the canonical NF- $\mathrm{kB}$ pathway and kinases catalyzing its phosphorylation. Furthermore, treatments with Dex or LPIL suppressed the phosphorylation of S276 of the RelA subunit, which would in turn inhibit the translocation of NF-kB into the nucleus, where it could interact with the promoter region of the IL8 gene.

\section{Acknowledgements}

We gratefully acknowledge the assistance of Mrs Asayo Imaoka with the microarray technology. This research was supported in part by "Academic Frontier" Project for Private Universities: matching fund subsidy from Ministry of Education, Culture, Sports, Science and Technology in 2007-2011, the Grants-in-Aid for Scientific Research (Kakenhi: 21390497, 22592078).

\section{References}

Agro, A., Langdon, C., Smith, F. \& Richards, C. D. (1996). Prostaglandin E2 enhances interleukin 8 (IL-8) and IL-6 but inhibits GMCSF production by IL-1 stimulated 
human synovial fibroblasts in vitro. J Rheumatol, Vol. 23, No. 5, pp. (862-868), issn 0315-162X.

Baggiolini, M., Dewald, B. \& Moser, B. (1994). Interleukin-8 and related chemotactic cytokines - CXC and CC chemokines, In: Adv Immunol, Vol 55, pp. 97-179).

Bartok, B. \& Firestein, G. S. (2010). Fibroblast-like synoviocytes: key effector cells in rheumatoid arthritis. Immunol Rev, Vol. 233, No. 1, pp. (233-255), issn 1600-065X (Electronic), 0105-2896 (Linking).

Borghaei, R. C., Rawlings, P. L. \& Mochan, E. (1998). Interleukin-4 suppression of interleukin-1-induced transcription of collagenase (MMP-1) and stromelysin 1 (MMP-3) in human synovial fibroblasts. Arthritis Rheum, Vol. 41, No. 8, pp. (13981406), issn 0004-3591.

Budihardjo, I., Oliver, H., Lutter, M., Luo, X. \& Wang, X. D. (1999). Biochemical pathways of caspase activation during apoptosis. Annu Rev Cell Dev Biol, Vol. 15, No., pp. (269290), issn 1081-0706.

Caristi, S., Piraino, G., Cucinotta, M., Valenti, A., Loddo, S. \& Teti, D. (2005). Prostaglandin $\mathrm{E}_{2}$ induces interleukin-8 gene transcription by activating C/EBP homologous protein in human T lymphocytes. J Biol Chem, Vol. 280, No. 15, pp. (14433-14442), issn 0021-9258.

Connell, L. \& McInnes, I. B. (2006). New cytokine targets in inflammatory rheumatic diseases. Best Pract Res Clin Rheumatol, Vol. 20, No. 5, pp. (865-878), issn 1521-6942.

Cozzolino, F., Torcia, M., Lucibello, M., Morbidelli, L., Ziche, M., Platt, J., Fabiani, S., Brett, J. \& Stern, D. (1993). Interferon-alpha and interleukin 2 synergistically enhance basic fibroblast growth factor synthesis and induce release, promoting endothelial cell growth. J Clin Invest, Vol. 91, No. 6, pp. (2504-2512), issn 0021-9738 (Print), 00219738 (Linking).

Dayer, J. M. (2002). The saga of the discovery of IL-1 and TNF and their specific inhibitors in the pathogenesis and treatment of rheumatoid arthritis. Joint Bone Spine, Vol. 69, No. 2, pp. (123-132), issn 1297-319X.

Dayer, J. M. (2004). The process of identifying and understanding cytokines: from basic studies to treating rheumatic diseases. Best Pract Res Clin Rheumatol, Vol. 18, No. 1, pp. (31-45), issn 1521-6942.

Demura, S., Yamaji, S. \& Ikemoto, Y. (2002). Effect of linear polarized near-infrared light irradiation on flexibility of shoulder and ankle joints. J Sports Med Phys Fitness, Vol. 42, No. 4, pp. (438-445), issn 0022-4707 (Print), 0022-4707 (Linking).

Feldmann, M. \& Maini, R. N. (1999). The role of cytokines in the pathogenesis of rheumatoid arthritis. Rheumatology, Vol. 38, No., pp. (3-7), issn 1462-0324.

Firestein, G. S. (1996). Invasive fibroblast-like synoviocytes in rheumatoid arthritis. Passive responders or transformed aggressors? Arthritis Rheum, Vol. 39, No. 11, pp. (17811790), issn 0004-3591.

Firestein, G. S. (2003). Evolving concepts of rheumatoid arthritis. Nature, Vol. 423, No. 6937, pp. (356-361), issn 0028-0836.

Firestein, G. S. (2007). Biomedicine: Every joint has a silver lining. Science, Vol. 315, No. 5814, pp. (952-953), issn 0036-8075, 1095-9203.

Goldring, S. R. (2003). Pathogenesis of bone and cartilage destruction in rheumatoid arthritis. Rheumatology, Vol. 42, No., pp. (11-16), issn 1462-0324. 
Han, S. K., Jeon, S. J., Miyazawa, K., Yi, S. Y. \& Yoo, Y. S. (2006). Enhancement of antiinflammatory tendency by SB203580, p38alpha specific inhibitor, in human fibroblast-like synoviocyte cell line, MH7A. Rheumatol Int, Vol. 26, No. 11, pp. (972978), issn 0172-8172 (Print), 0172-8172 (Linking).

Hebert, C. A. \& Baker, J. B. (1993). Interleukin-8 - a review. Cancer Invest, Vol. 11, No. 6, pp. (743-750), issn 0735-7907.

Houssiau, F. A., Devogelaer, J. P., Van Damme, J., de Deuxchaisnes, C. N. \& Van Snick, J. (1988). Interleukin-6 in synovial fluid and serum of patients with rheumatoid arthritis and other inflammatory arthritides. Arthritis Rheum, Vol. 31, No. 6, pp. (784-788), issn 0004-3591 (Print), 0004-3591 (Linking).

Huber, L. C. (2006). Synovial fibroblasts: key players in rheumatoid arthritis. Rheumatology, Vol. 45, No. 6, pp. (669-675), issn 1462-0324, 1462-0332.

Hunter, C. A. (2005). New IL-12-family members: IL-23 and IL-27, cytokines with divergent functions. Nat Rev Immunol, Vol. 5, No. 7, pp. (521-531), issn 1474-1733.

Iwanaga, T., Shikichi, M., Kitamura, H., Yanase, H. \& Nozawa-Inoue, K. (2000). Morphology and functional roles of synoviocytes in the joint. Arch Histol Cytol, Vol. 63, No. 1, pp. (17-31), issn 0914-9465 (Print), 0914-9465 (Linking).

Kirwan, J., \& Power L. (2007). Glucocorticoids: action and new therapeutic insights in rheumatoid arthritis. Curr Opin Rheumatol, Vol. 19, No. 3, pp. (233-237).

King, M. R. \& Hammer, D. A. (2001). Multiparticle adhesive dynamics: Hydrodynamic recruitment of rolling leukocytes. Proc Natl Acad Sci USA, Vol. 98, No. 26, pp. (14919-14924), issn 0027-8424.

Matsusaka, T., Fujikawa, K., Nishio, Y., Mukaida, N., Matsushima, K., Kishimoto, T. \& Akira, S. (1993). Transcription factors NF-IL6 and NF-kappa B synergistically activate transcription of the inflammatory cytokines, interleukin 6 and interleukin 8. Proc Natl Acad Sci USA, Vol. 90, No. 21, pp. (10193-10197), issn 0027-8424 (Print), 0027-8424 (Linking).

Mattioli, I., Sebald, A., Bucher, C., Charles, R. P., Nakano, H., Doi, T., Kracht, M. \& Schmitz, M. L. (2004). Transient and selective NF-kappa B p65 serine 536 phosphorylation induced by $\mathrm{T}$ cell costimulation is mediated by I kappa B kinase beta and controls the kinetics of p65 nuclear import. J Immunol, Vol. 172, No. 10, pp. (6336-6344), issn 0022-1767 (Print), 0022-1767 (Linking).

Mauviel, A., Teyton, L., Bhatnagar, R., Penfornis, H., Laurent, M., Hartmann, D., Bonaventure, J., Loyau, G., Saklatvala, J. \& Pujol, J. P. (1988). Interleukin-1 alpha modulates collagen gene expression in cultured synovial cells. Biochem J, Vol. 252, No. 1, pp. (247-255), issn 0264-6021 (Print), 0264-6021 (Linking).

Mendonça, J. A., Marques-Neto, J. F., Samara, A. M. \& Appenzeller, S. (2011). Increased levels of rheumatoid factors after TNF inhibitor in rheumatoid arthritis. Rheumatol Int, Vol., No.), issn 0172-8172, 1437-160X.

Miyazawa, K., Mori, A. \& Okudaira, H. (1998). Establishment and characterization of a novel human rheumatoid fibroblast-like synoviocyte line, MH7A, immortalized with SV40 T antigen. J Biochem, Vol. 124, No. 6, pp. (1153-1162), issn 0021-924X (Print), 0021-924X (Linking).

Morita, Y., Yamamura, M., Nishida, K., Harada, S., Okamoto, H., Inoue, H., Ohmoto, Y., Modlin, R. L. \& Makino, H. (1998). Expression of interleukin-12 in synovial tissue 
from patients with rheumatoid arthritis. Arthritis Rheum, Vol. 41, No. 2, pp. (306314), issn 0004-3591.

Nagashima, M., Yoshino, S., Aono, H., Takai, M. \& Sasano, M. (1999). Inhibitory effects of anti-rheumatic drugs on vascular endothelial growth factor in cultured rheumatoid synovial cells. Clin Exp Immunol, Vol. 116, No. 2, pp. (360-365), issn 0009-9104.

O'Dell, J. R. (2004). Therapeutic strategies for rheumatoid arthritis. N Engl J Med, Vol. 350, No. 25, pp. (2591-2602), issn 1533-4406 (Electronic), 0028-4793 (Linking).

Pap, T., Muller-Ladner, U., Gay, R. E. \& Gay, S. (2000). Fibroblast biology. Role of synovial fibroblasts in the pathogenesis of rheumatoid arthritis. Arthritis Res, Vol. 2, No. 5 , pp. (361-367), issn 1465-9913.

Rathanaswami, P., Hachicha, M., Sadick, M., Schall, T. J. \& McColl, S. R. (1993). Expression of the cytokine RANTES in human rheumatoid synovial fibroblasts. Differential regulation of RANTES and interleukin- 8 genes by inflammatory cytokines. J Biol Chem, Vol. 268, No. 8, pp. (5834-5839), issn 0021-9258 (Print), 0021-9258 (Linking).

Robinson, D. R., Tashjian, A. H. \& Levine, L. (1975). Prostaglandin-stimulated boneresorption by rheumatoid synovial: possible mechanism for bone destruction in rheumatoid-arthritis. J Clin Invest, Vol. 56, No. 5, pp. (1181-1188), issn 0021-9738.

Rothe, M., Pan, M. G., Henzel, W. J., Ayres, T. M. \& Goeddel, D. V. (1995). The TNFR2-TRAF signaling complex contains two novel proteins related to baculoviral inhibitor of apoptosis proteins. Cell, Vol. 83, No. 7, pp. (1243-1252), issn 0092-8674 (Print), 00928674 (Linking).

Saag, K. G., Teng, G. G., Patkar, N. M., Anuntiyo, J., Finney, C., Curtis, J. R., Paulus, H. E., Mudano, A., Pisu, M., Elkins-Melton, M., Outman, R., Allison, J. J., Almazor, M. S., Bridges, S. L., Chatham, W. W., Hochberg, M., Maclean, C., Mikuls, T., Moreland, L. W., O'Dell, J., Turkiewicz, A. M. \& Furst, D. E. (2008). American College of Rheumatology 2008 recommendations for the use of nonbiologic and biologic disease-modifying antirheumatic drugs in rheumatoid arthritis. Arthritis Rheum, Vol. 59, No. 6, pp. (762-784), issn 00043591, 15290131.

Sakurai, H., Chiba, H., Miyoshi, H., Sugita, T. \& Toriumi, W. (1999). IkappaB kinases phosphorylate NF-kappaB p65 subunit on serine 536 in the transactivation domain. J Biol Chem, Vol. 274, No. 43, pp. (30353-30356), issn 0021-9258 (Print), 0021-9258 (Linking).

Sakurai, H. (2003). Tumor Necrosis Factor- -induced IKK Phosphorylation of NF- B p65 on Serine 536 Is Mediated through the TRAF2, TRAF5, and TAK1 Signaling Pathway. $J$ Biol Chem, Vol. 278, No. 38, pp. (36916-36923), issn 0021-9258, 1083-351X.

Shibata, Y., Ogura, N., Yamashiro, K., Takashiba, S., Kondoh, T., Miyazawa, K., Matsui, M. \& Abiko, Y. (2005). Anti-inflammatory effect of linear polarized infrared irradiation on interleukin-1 beta-induced chemokine production in MH7A rheumatoid synovial cells. Lasers Med Sci, Vol. 20, No. 3-4, pp. (109-113), issn 0268-8921.

Shibata, Y., Araki, H., Oshitani, T., Imaoka, A., Matsui, M., Miyazawa, K. \& Abiko, Y. (2009a). Effects of linear polarized infrared light irradiation on the transcriptional regulation of IL-8 expression in IL-1 beta-stimulated human rheumatoid synoviocytes involves phosphorylation of the NF-kappa B RelA subunit. $J$ Photochem Photobiol B-Biol, Vol. 94, No. 3, pp. (164-170), issn 1011-1344.

Shibata, Y., Kasai, H., Shimada, M., Koitabashi, T., Arai, T., Sai, R., Terao, H., Horikiri, M., Negishi, H., Miyazawa, K. \& Abiko, Y. (2009b). IL-1 beta stimulates IL-8 
production, including prostaglandin $\mathrm{E}_{2}$ receptor EP4-triggered pathways, in synoviocyte MH7A cells. Mol Med Rep, Vol. 2, No. 3, pp. (359-363), issn 1791-2997.

Smolen, J. S. \& Steiner, G. (2003). Therapeutic strategies for rheumatoid arthritis. Nat Rev Drug Discov, Vol. 2, No. 6, pp. (473-488), issn 14741776, 14741784.

Standiford, T. J., Kunkel, S. L., Rolfe, M. W., Evanoff, H. L., Allen, R. M. \& Strieter, R. M. (1992). Regulation of human alveolar macrophage-derived and blood monocytederived interleukin-8 by prostaglandin-E2 and dexamethasone. Am J Respir Cell Mol Biol, Vol. 6, No. 1, pp. (75-81), issn 1044-1549.

Suissa, S., Bernatsky, S. \& Hudson, M. (2006). Antirheumatic drug use and the risk of acute myocardial infarction. Arthritis Rheum, Vol. 55, No. 4, pp. (531-536), issn 0004-3591 (Print), 0004-3591 (Linking).

Sun, H. B. \& Yokota, H. (2002). Reduction of cytokine-induced expression and activity of MMP-1 and MMP-13 by mechanical strain in MH7A rheumatoid synovial cells. Matrix Biol, Vol. 21, No. 3, pp. (263-270), issn 0945-053X.

Suzuki, M., Hashizume, M., Yoshida, H., Shiina, M. \& Mihara, M. (2010). IL-6 and IL-1 synergistically enhanced the production of MMPs from synovial cells by upregulating IL-6 production and IL-1 receptor I expression. Cytokine, Vol. 51, No. 2, pp. (178-183), issn 10434666.

Takayama, K., Garcia-Cardena, G., Sukhova, G. K., Comander, J., Gimbrone, M. A. \& Libby, P. (2002). Prostaglandin $E_{2}$ suppresses chemokine production in human macrophages through the EP4 receptor. J Biol Chem, Vol. 277, No. 46, pp. (4414744154), issn 0021-9258.

Tolboom, T. C. A., van der Helm-Van Mil, A. H. M., Nelissen, R. G. H. H., Breedveld, F. C., Toes, R. E. M. \& Huizinga, T. W. J. (2005). Invasiveness of fibroblast-like synoviocytes is an individual patient characteristic associated with the rate of joint destruction in patients with rheumatoid arthritis. Arthritis Rheum, Vol. 52, No. 7, pp. (1999-2002), issn 0004-3591, 1529-0131.

Trebino, C. E., Stock, J. L., Gibbons, C. P., Naiman, B. M., Wachtmann, T. S., Umland, J. P., Pandher, K., Lapointe, J. M., Saha, S., Roach, M. L., Carter, D., Thomas, N. A., Durtschi, B. A., McNeish, J. D., Hambor, J. E., Jakobsson, P. J., Carty, T. J., Perez, J. R. \& Audoly, L. P. (2003). Impaired inflammatory and pain responses in mice lacking an inducible prostaglandin E synthase. Proc Natl Acad Sci USA, Vol. 100, No. 15, pp. (9044-9049), issn 0027-8424.

Volin, M. V., Harlow, L. A., Woods, J. M., Campbell, P. L., Amin, M. A., Tokuhira, M. \& Koch, A. E. (1999). Treatment with sulfasalazine or sulfapyridine, but not 5aminosalicyclic acid, inhibits basic fibroblast growth factor-induced endothelial cell chemotaxis. Arthritis Rheum, Vol. 42, No. 9, pp. (1927-1935), issn 0004-3591 (Print), 0004-3591 (Linking).

Wertheim, W. A., Kunkel, S. L., Standiford, T. J., Burdick, M. D., Becker, F. S., Wilke, C. A., Gilbert, A. R. \& Strieter, R. M. (1993). Regulation of neutrophil-derived Il-8. The role of prostaglandin $\mathrm{E}_{2}$, dexamethasone, and Il-4. J Immunol, Vol. 151, No. 4, pp. (2166-2175), issn 0022-1767.

Yang, F., Tang, E., Guan, K. \& Wang, C. Y. (2003). IKK beta plays an essential role in the phosphorylation of RelA/p65 on serine 536 induced by lipopolysaccharide. J Immunol, Vol. 170, No. 11, pp. (5630-5635), issn 0022-1767 (Print), 0022-1767 (Linking). 
Yokoyama, K. \& Oku, T. (1999). Rheumatoid arthritis-affected temporomandibular joint pain analgesia by linear polarized near infrared irradiation. Can J Anaesth, Vol. 46, No. 7, pp. (683-687), issn 0832-610X (Print), 0832-610X (Linking).

Yokoyama, K. \& Sugiyama, K. (2003). Influence of linearly polarized near-infrared irradiation on deformability of human stored erythrocytes. J Clin Laser Med Surg, Vol. 21, No. 1, pp. (19-22), issn 1044-5471 (Print), 1044-5471 (Linking).

$\mathrm{Yu}, \mathrm{Y}$. \& Chadee, K. (1998). Prostaglandin $\mathrm{E}_{2}$ stimulates IL-8 gene expression in human colonic epithelial cells by a posttranscriptional mechanism. J Immunol, Vol. 161, No. 7, pp. (3746-3752), issn 0022-1767.

Zhong, H., May, M. J., Jimi, E. \& Ghosh, S. (2002). The phosphorylation status of nuclear NFkappa B determines its association with CBP/p300 or HDAC-1. Mol Cell, Vol. 9, No. 3, pp. (625-636), issn 1097-2765 (Print), 1097-2765 (Linking). 


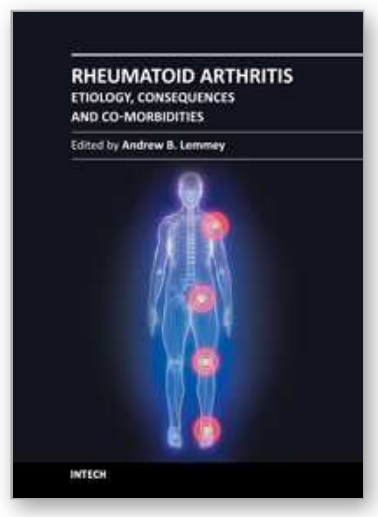

\author{
Rheumatoid Arthritis - Etiology, Consequences and Co-Morbidities \\ Edited by Dr. Andrew Lemmey
}

ISBN 978-953-307-847-2

Hard cover, 304 pages

Publisher InTech

Published online 11, January, 2012

Published in print edition January, 2012

The purpose of this book is to provide up-to-date, interesting, and thought-provoking perspectives on various aspects of research into current and potential treatments for rheumatoid arthritis (RA). This book features 16 chapters, with contributions from numerous countries (e.g. UK, USA, Japan, Sweden, Spain, Ireland, Poland, Norway), including chapters from internationally recognized leaders in rheumatology research. It is anticipated that Rheumatoid Arthritis - Etiology, Consequences and Co-Morbidities will provide both a useful reference and source of potential areas of investigation for research scientists working in the field of RA and other inflammatory arthropathies.

\title{
How to reference
}

In order to correctly reference this scholarly work, feel free to copy and paste the following:

Yasuko Shibata and Yoshimitsu Abiko (2012). Profiling Inflammatory Genes and Signaling Pathways in Rheumatoid Synoviocytes for RA Light Therapy, Rheumatoid Arthritis - Etiology, Consequences and CoMorbidities, Dr. Andrew Lemmey (Ed.), ISBN: 978-953-307-847-2, InTech, Available from:

http://www.intechopen.com/books/rheumatoid-arthritis-etiology-consequences-and-co-morbidities/profilinginflammatory-genes-and-signaling-pathways-in-rheumatoid-synoviocytes-for-ra-light-therapy

\section{INTECH}

open science | open minds

\section{InTech Europe}

University Campus STeP Ri

Slavka Krautzeka 83/A

51000 Rijeka, Croatia

Phone: +385 (51) 770447

Fax: +385 (51) 686166

www.intechopen.com

\section{InTech China}

Unit 405, Office Block, Hotel Equatorial Shanghai

No.65, Yan An Road (West), Shanghai, 200040, China

中国上海市延安西路65号上海国际贵都大饭店办公楼 405 单元

Phone: +86-21-62489820

Fax: +86-21-62489821 
(C) 2012 The Author(s). Licensee IntechOpen. This is an open access article distributed under the terms of the Creative Commons Attribution 3.0 License, which permits unrestricted use, distribution, and reproduction in any medium, provided the original work is properly cited. 